\title{
SALUD, SALUD MENTAL, BIOÉTICA. INTERFACES DIGNAS DE ANÁLISIS
}

\author{
Fernando Lolas Stepke
}

La preparación de este número de Acta Bioethica es un buen ejemplo de lo que acontece con las designaciones empleadas por expertos y profanos en el campo amplio de lo que conocemos como "ciencias de la salud".

A riesgo de ser provocativo, pienso que la expresión "salud mental" no es adecuada. Segrega, a veces necesaria pero en ocasiones innecesariamente, una forma o tipo de salud del bienestar general. Un número reciente de una prestigiosa revista médica se editó bajo el lema "no hay salud sin salud mental", lo que, aun insinuando lo contrario, refuerza esta idea: la salud es una sola construcción conceptual. Y es más: involucra un momento axiológico esencial, pues salud siempre es cosa buena; no tenerla es intrínsecamente malo. Salud mental, como expresión, parece sugerir que hay aspectos de la vida -los mentales, cuya definición es ambigua- que pueden estar bien, aun cuando otros - probablemente los no mentales- podrían estar mal.

Es cierto que, por ejemplo, una persona con trastornos cognitivos severos puede gozar de una fisiología óptima en sus aparatos respiratorio, circulatorio o gastrointestinal. Mas la salud, como bienestar, según reza la consagrada definición de la OMS, no es una sumatoria de "saludes" parciales sino un estado global, una composición holística. No podría decirse que las personas con deficiencia intelectual son enfermas en lo mental y sanas en lo somático, a menos que se aplique el sustantivo "dualismo práctico", que la mayoría de los filósofos-médicos dice repudiar. No tendríamos tamaña historia de "modelos", como los integradores, bio-psico-sociales, holísticos, psicosomáticos o antropológicos, si realmente la condición unitaria del ser humano fuera asunto de convicciones universales. Si así fuera, no sería necesario decirlo, como sugerí hace años en mi libro "La perspectiva psicosomática en medicina" y como me convenció la larga experiencia con la más compleja de las tradiciones integradoras, la de la Escuela de Heidelberg, la cual conocí a través de mi maestro, Paul Christian, discípulo a su vez de Viktor von Weizsäcker, cuyas intuiciones en este terreno aún no han sido completamente examinadas.

Precisamente, la alusión a esa tradición y su relación con lo que los estadounidenses empezaron a llamar "bioética" en los años 70 del siglo XX, ignorando que el vocablo lo había acuñado Fritz Jahr en 1927, es un tema de interés personal para mí. Podría decirse que la incursión en ámbitos aparentemente tan diversos como la neurosis de renta, la seguridad social, la distonía neurovegetativa y los trastornos funcionales es un entrecruce de discursos que luego, en forma menos elegante pero quizá más práctica, se propusieron quienes dicen practicar la bioética en su versión de ética médica. Que hay otras versiones de bioética, como la ecológica, la global o la decisional, no requiere mayores comentarios, pero al planear este número queríamos aportes a la interfaz entre áreas que laxamente se conocen como neurociencia, psiquiatría clínica, investigación en salud mental y algunas más. Lo que nos interesaba era la opinión de personas versadas en el oficio sobre el papel de la reflexión ética. $\mathrm{O}$, a la inversa, lo que dirían los expertos en filosofía práctica sobre el quehacer psiquiátrico. No desmerece el valor de lo que aquí se publica si digo que deberemos dedicar otro número a estos temas. Lo que aquí queda publicado bien publicado está, pero no agota el tema. Es más, no siempre supimos, el editor y yo, transmitir a los potenciales autores nuestra demanda. Y tal vez deba agregar que algunos textos no pasaron el cedazo de los revisores.

Por tanto, y resumiendo, nos falta más material sobre esa área problemática en el entrecruce de salud, salud mental y bioética. Un artículo ejemplar en este número lo debemos al profesor de Nápoles Mario Maj, presidente de la Asociación Mundial de Psiquiatría, quien aborda el tema de los conflictos de interés. Esperaríamos ver en el futuro a un investigador en neurociencias ilustrando a nuestros lectores sobre neuroética y a un psiquiatra clínico elaborando las complejas relaciones interpersonales de la psicoterapia. Los plazos para esta edición se cumplieron,

1 Lolas F. La perspectiva psicosomática en medicina. 2a edición, Santiago de Chile: Editorial Universitaria; 1995. 
algunos autores no respondieron a nuestra demanda con la celeridad o la calidad que requiere una revista internacional, y el tema es vasto, complejo y ambiguo. Cumplimos con nuestros plazos, hicimos el arduo trabajo de edición y complementamos lo recibido con artículos misceláneos, escogidos de entre los muchos que esperan en la línea de publicación de Acta Bioethica, tras ser aprobados por los revisores.

Tengo para mí que una revista, por técnica que se perfile, debe contener espacios flexibles de diálogo e interacción con los lectores. Una ya larga experiencia en las lides editoriales me ha convencido de la escasa aceptación de "cartas al editor" y "comentarios" publicados en conjunto con los artículos originales. Seguimos manteniendo introducciones como ésta, que en su informalidad informan y en su franqueza valoran, como asimismo las recensiones y noticias bibliográficas, a veces de valor perdurable. No cuentan, como es bien sabido, como fuente de citaciones y por eso las revistas altamente especializadas suelen no favorecer estos aspectos menos especializados. Pero la bioética aún no se configura como un área de contornos tan nítidos que pueda excluirlos. Es más. Examinando el entorno latinoamericano, con sus pintorescas efusiones de antiimperialismo y manidas consignas que tratan de hacerse pasar por preocupaciones serias por los derechos humanos, aún no deberíamos darnos por satisfechos sobre el estado actual de este discurso, al menos en el continente de marras. Lo lamentable es que buenas causas, sin duda alguna, son trivializadas por mala argumentación. Y lamentando todos la inequidad en el mundo, la violación de los derechos de las personas o el doble estándar de algunos sectores de la industria y la academia en temas éticos, la mejor manera de abordarlos no es con gritos, imprecaciones o ideaciones paranoides de corte conspirativo, sino con la reflexión, la tolerancia por el argumento ajeno y la necesaria solvencia intelectual que tales asuntos demandan.

Si Acta Bioethica puede aspirar a algún mérito que perdure, para los que en ella laboramos pienso que debiera ser el de constituir precisamente el espacio plural, tolerante, sobrio y reflexivo para una construcción disciplinaria. 